\title{
Foreword by the Director-General of UNIDO
}

Technological change is key to achieving sustainable development. It is the essential basis for economic growth - the sine qua non for poverty reduction - and for the preservation of environmental quality.

UNIDO fully appreciates the importance of firm-level technological change for initiating a path of sustainable development. It works actively with the relevant national and international stakeholders to foster productivity growth in developing countries and in economies in transition. Growth in productivity results from producing goods more efficiently, producing goods of better quality and producing new goods. All these involve innovation and technological change.

In broad terms, technological change can be defined as any change in the way in which inputs are transformed into outputs. Undertaking such a change requires information, knowledge and skills on the part of the firm as well as a conducive business environment. Understanding this change process and its determinants is obviously crucial for stimulating the growth of higher-value production in developing countries. Moreover, an improved understanding of this process is instrumental in defining how public policy can shape technological change in more environmentally benign directions. While recent studies of technological change in developing countries have greatly advanced our insight into this process, more theoretical and empirical work is still needed - particularly in terms of its environmental aspects.

It is for this reason that UNIDO has undertaken this research to determine the factors that govern, in various circumstances, the adoption of environmentally sound technology (EST), which includes a variety of cleaner technology measures and pollution control solutions. This research aims to contribute to the debate on this subject and to further the understanding of how environmentally sound technological change can best be encouraged in developing countries. It underscores once more UNIDO's commitment to sustainable industrial development and builds upon the insights gained from its years of technical cooperation in technology transfer and the promotion of cleaner production. The results of this research will feed into the Organization's policy advisory services and technical cooperation interventions. 